\title{
Miniaturized Human 3D Motion Input
}

\author{
Kynan Eng \\ Institute of Neuroinformatics \\ University of Zurich and ETH Zurich \\ Switzerland
}

\section{Introduction}

Imagine that you are sitting on a train, standing in a queue or walking down the street. You are, like a majority of people in the world, carrying one or more mobile computing devices. It could be a mobile telephone, a portable media player, a personal digital assistant (PDA) or a portable gaming console (e.g. Nintendo DS, Sony Playstation Portable). Your particular device has 3D graphics capabilities, and you have some application - perhaps a game, a navigation tool or a computer-aided design (CAD) model - that needs 3D input. How do you provide 3D input to your device as intuitively and quickly as possible, preferably using only one hand? And how can you provide the input while standing and without needing to use a stable surface such as a table or wall?

An increasing number of hand-held computers, portable gaming devices and mobile telephones are sufficiently powerful to run $3 \mathrm{D}$ applications. There is thus a need for miniature one-handed input devices that combine small size, many input degrees of freedom (DOF) and acceptable usability compromises. Users of 3D applications need to manipulate virtual objects in up to six degrees of rotational and translation freedom (DOF). A wide range of devices for providing the required input is already available on desktop computer and gaming console platforms. However, due to technological and human physiological constraints none of them can be easily scaled down to a form that could conceivably be part of a truly portable device. Here I detail the requirements for a useable portable "walk-around" 3D input device, reviews currently available 3D input technologies and describe a candidate design fulfilling the requirements.

\section{3D Input Technologies}

\subsection{Existing Technologies}

How many input degrees of freedom are necessary to control a 3D software application? The answer depends on the application. The most common families of 3D applications, and the currently most popular ways of controlling them, are:

- Driving simulations: 3DOF total - left hand 1DOF (steering wheel), right hand or feet 2DOF (keyboard/pedals: accelerate, brake) 
- $\quad$ Flight simulators (fixed-wing): 4DOF total - right hand 3DOF (joystick: nose up/down, bank left/right, rudder), left hand 1DOF (throttle: thrust).

- First-person games ("ego shooters") or virtual world free navigation: 4DOF total right hand 3DOF (mouse: look left-right, look up-down), left hand 2DOF (keyboard: torso left/right, torso forwards/backwards). Many games include extra special movements such as leaning, crawling and jumping which are controlled using the same DOFs with an extra key or button press.

- CAD models: 6DOF total - left hand 6DOF (SpaceBall/SpaceNavigator: translate $X$, $\mathrm{Y}, \mathrm{Z}$ and rotate $\mathrm{X}, \mathrm{Y}, \mathrm{Z}$ )

Examples of the most popular devices implementing these control methods are listed and described in Table 1. Note that in controller jargon, a "digital" input is one which uses on/off buttons or switches, and an "analog" input is one that allows graded input on an axis with multiple-bit digital output resolution. The terms "aDOF" and "dDOF" are used to refer to analog and digital degrees of freedom.

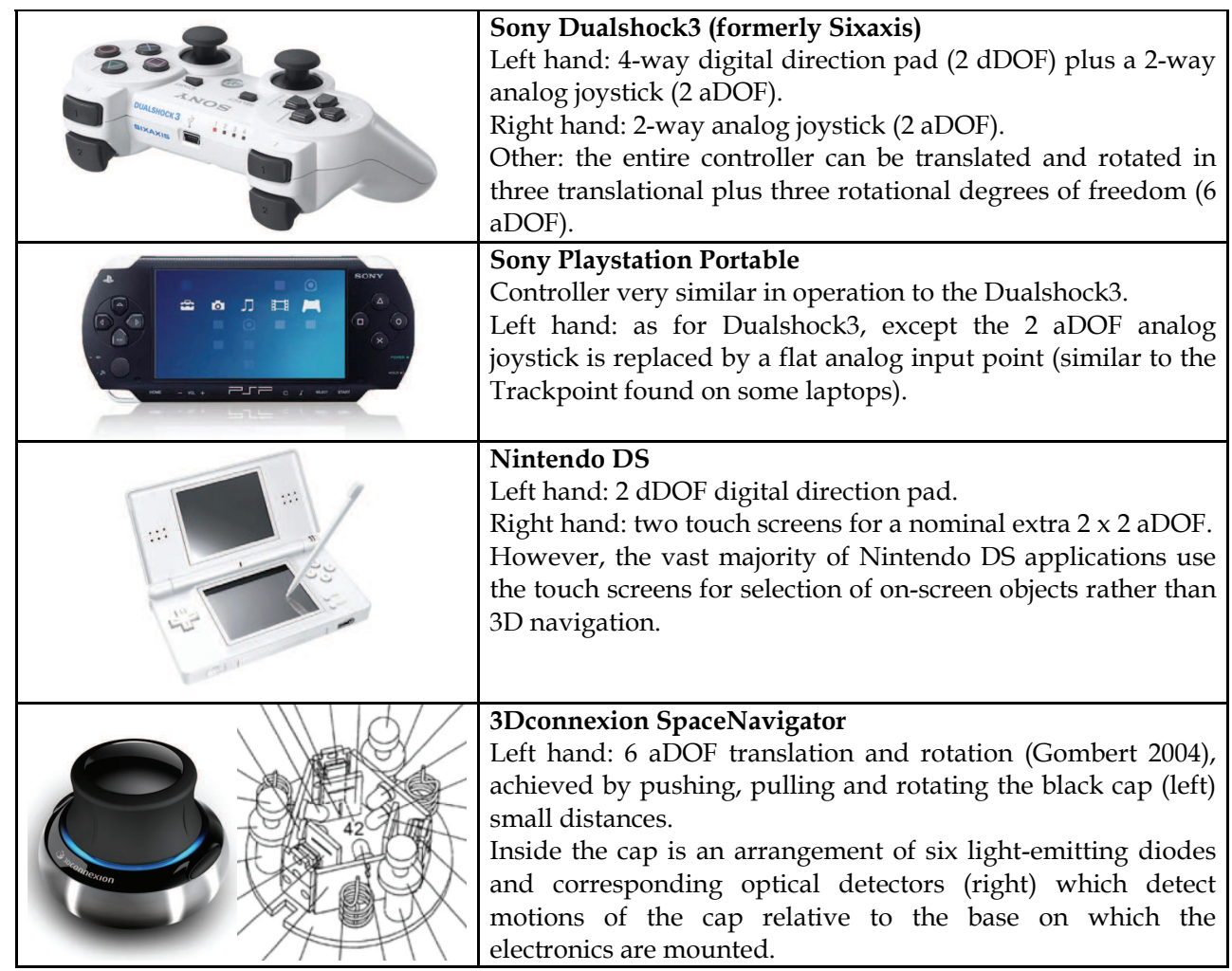




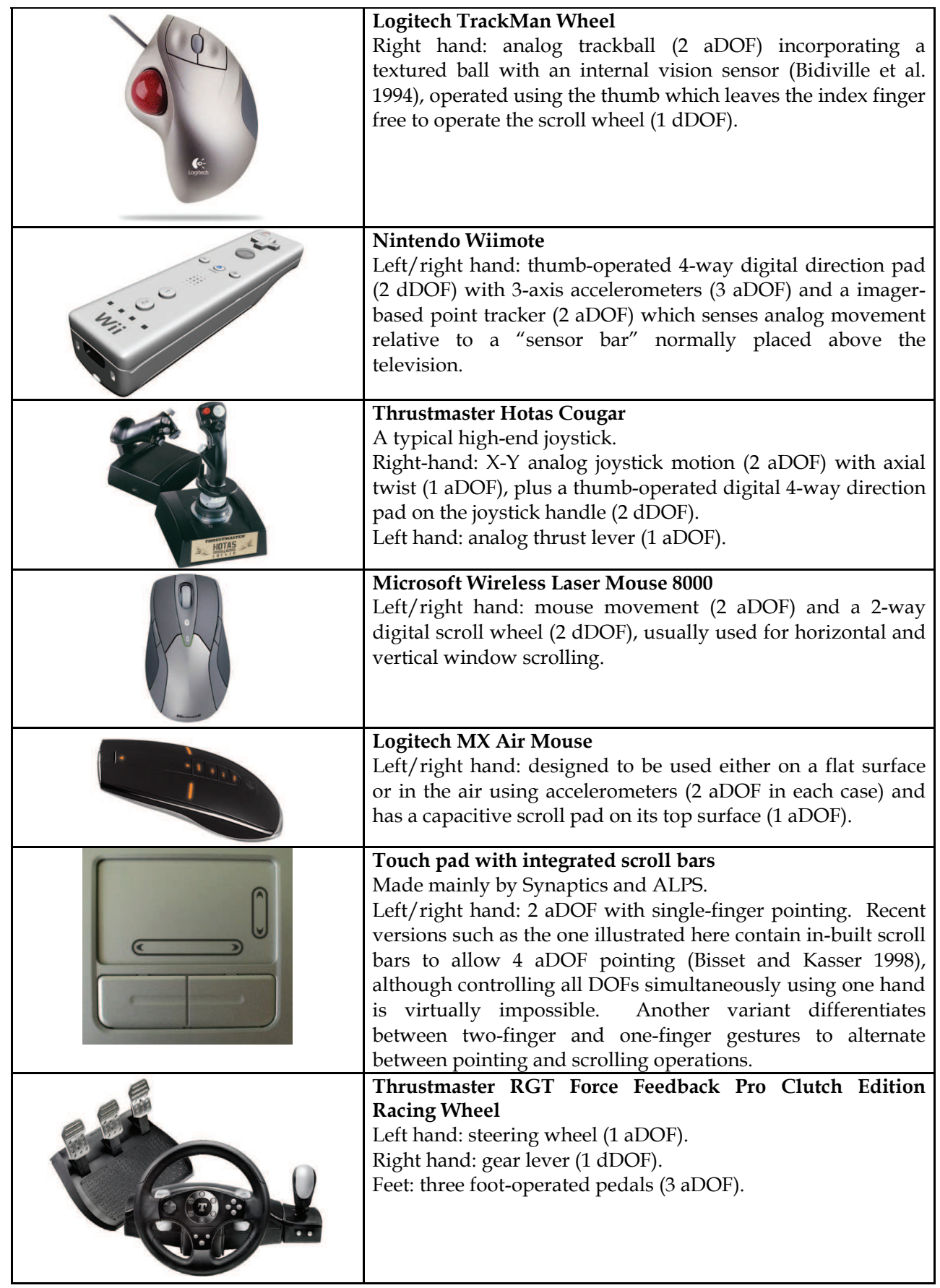




\begin{tabular}{|l|l|}
\hline ARToolkit \\
An open-source software library (ARToolworks 2007) which \\
provides 6 aDOF camera tracking of specially designed \\
markers. Has been used to produce a 6 aDOF mouse (Woods \\
et al. 2003). ARToolkit and its related projects (ARToolkit+, \\
ARTag) are examples of a class of "outside-in" trackers which \\
use an imaging device to track special markers attached to an \\
object to be manipulated.
\end{tabular}

Table 1. Description of currently available 3D controllers.

\subsection{Requirements}

An ideal miniature walk-around 3D input device would:

- $\quad$ provide for input in up to six independent analog DOF (3 translation plus 3 rotation).

- be operable using only one hand, with the other hand free to support the device and provide command input.

- work reliably even when the user and device are moving in unknown directions, either on foot or standing on a bus.

- be small enough to be mounted on a mobile computing device such as a mobile telephone or ultra-mobile PC.

- not require any extra devices to be worn or carried around, apart from the mobile computing device itself (optional).

- provide reasonable accuracy.

- be insensitive to everyday interference from light, sound and magnetic fields.

- be cheap and easy to manufacture.

Table 2 shows how the input devices described in the previous section match up against each other when miniaturized in terms of usability, manufacturability and implementation cost. The above-listed requirements act as strong constraints on the range of feasible input devices. In fact, there is currently no available device that satisfies all of the requirements. Most of the listed input devices support only 2-4 DOF in one-handed operation, while more degrees of freedom are very difficult to achieve. Since the user is not attached to a fixed reference frame such as a table or wall, the computing device itself must act as the reference frame for measuring movements. In unstable environments where the user can be moving around, free-floating inertial input devices such as the Sony Dualshock3, the Logitech MX Air Mouse, the ARToolkit tracker and the Nintendo Wii-mote accelerometers are unsuitable. The Wii-mote imaging sensor is also unsuitable since it uses an imaging sensor which would prone to interference from stray light and bright reflections.

The device which comes the closest to meeting all of the requirements is the 6 DOF SpaceNavigator from 3Dconnexion. It provides one-handed control which can be attached to any computing device by using an arrangement of springs and optical sensors inside the device's hand grip. However, the required volume of the custom sensor inside the hand grip currently limits its minimum size to about $4 \mathrm{~cm}$ diameter, making it currently unsuitable for ultra-mobile applications. It may be possible to reduce the size of the sensor further, but miniaturizing the multiple discrete parts in the sensor which include light- 
emitting diodes, several springs and metal stop elements (Gombert 2004) could affect manufacturability and therefore cost. What would be ideal is a that works as well as the SpaceNavigator, but uses fewer discrete parts and can be easily miniaturized.

\begin{tabular}{|c|c|c|}
\hline \multirow{2}{*}{$\begin{array}{l}\text { Existing Controller } \\
\text { Native DOFs }\end{array}$} & \multicolumn{2}{|c|}{ Miniaturized for 1-handed walk-around } \\
\hline & 1-handed walk-around usability & \begin{tabular}{|l|} 
Manufacturability Cost \\
\end{tabular} \\
\hline $\begin{array}{l}\text { Sony Dualshock3 } \\
4 \text { analog: } 2 \text { joysticks } \\
2 \text { digital: direction pad } \\
6 \text { analog: accel. + gyroscope }\end{array}$ & $\begin{array}{l}\text { Good for } 2 \mathrm{DOF} \text { only } \\
\text { Moderate for } 2+2 \mathrm{DOF} \\
\text { Poor for } 6 \mathrm{DOF} \text { (no reference } \\
\text { point for whole-body motion) }\end{array}$ & $\begin{array}{l}\text { Good } \\
\text { Low }\end{array}$ \\
\hline $\begin{array}{l}\text { Sony PSP } \\
2 \text { analog: trackpoint } \\
2 \text { digital: direction pad }\end{array}$ & $\begin{array}{l}\text { Good for } 2 \mathrm{DOF} \\
\text { Moderate for } 2+2 \mathrm{DOF}\end{array}$ & $\begin{array}{l}\text { Good } \\
\text { Low }\end{array}$ \\
\hline $\begin{array}{l}\text { Nintendo DS } \\
2 \text { digital: direction pad } \\
4 \text { analog: } 2 \text { touchscreens }\end{array}$ & Good for 2DOF only & $\begin{array}{l}\text { Good } \\
\text { Low }\end{array}$ \\
\hline $\begin{array}{l}\text { 3Dconnexion SpaceNavigator } \\
6 \text { analog: custom optical-spring } \\
\text { sensor }\end{array}$ & Good for 6DOF & $\begin{array}{lll}\text { Poor: sensor must fit } \\
\text { inside cap } & & \\
\text { Medium } & & \\
\end{array}$ \\
\hline $\begin{array}{l}\text { Logitech TrackMan Wheel } 2 \\
\text { analog: trackball } \\
1 \text { digital: scroll wheel }\end{array}$ & Good for 2+1DOF & $\begin{array}{l}\text { Good } \\
\text { Low }\end{array}$ \\
\hline $\begin{array}{l}\text { Nintendo Wii-mote } \\
2 \text { analog: screen pointer } \\
2 \text { digital: direction pad } \\
3 \text { analog: accelerometers }\end{array}$ & $\begin{array}{l}\text { Good for } 2 \mathrm{DOF} \\
\text { Poor for 2+2DOF: no fixed } \\
\text { reference point available for } \\
\text { screen pointer }\end{array}$ & $\begin{array}{l}\text { Good } \\
\text { Low }\end{array}$ \\
\hline $\begin{array}{l}\text { Thrustmaster Hotas Cougar } 4 \\
\text { analog: joystick with stick rotate, } \\
\text { throttle } \\
2 \text { digital: direction pad }\end{array}$ & $\begin{array}{l}\text { Good for 3DOF } \\
\text { Moderate for 3+2DOF: move } \\
\text { joystick with hand while } \\
\text { thumb/finger controls direction } \\
\text { pad }\end{array}$ & $\begin{array}{l}\text { Moderate } \\
\text { Low }\end{array}$ \\
\hline $\begin{array}{l}\text { Microsoft Wireless Laser Mouse } \\
\mathbf{8 0 0 0} \\
2 \text { analog: mouse } \\
2 \text { digital: 2D scroll wheel }\end{array}$ & $\begin{array}{l}\text { Poor: must keep mouse on large } \\
\text { flat stable surface }\end{array}$ & $\begin{array}{l}\text { Good } \\
\text { Low }\end{array}$ \\
\hline \begin{tabular}{l}
\multicolumn{3}{l}{ Logitech MX Air Mouse } \\
2 analog: mouse surface or \\
accelerometers in air \\
1 analog: scroll pad
\end{tabular} & $\begin{array}{l}\text { Moderate for 3DOF: no fixed } \\
\text { reference point for air operation }\end{array}$ & $\begin{array}{l}\text { Good } \\
\text { Medium }\end{array}$ \\
\hline $\begin{array}{l}\text { Touch pad with scroll bars } \\
4 \text { analog: touch pad, scroll bars }\end{array}$ & $\begin{array}{l}\text { Moderate: can only actuate } 2-3 \\
\text { DOF at a time with one hand }\end{array}$ & $\begin{array}{l}\text { Good } \\
\text { Low }\end{array}$ \\
\hline $\begin{array}{l}\text { ARToolkit } \\
6 \text { analog: camera tracking of marker } \\
\text { patch pose }\end{array}$ & $\begin{array}{l}\text { Poor: highly sensitive to ambient } \\
\text { lighting conditions, requires } \\
\text { extra object to be carried around, } \\
\text { CPU intensive }\end{array}$ & $\begin{array}{l}\text { Good } \\
\text { Low }\end{array}$ \\
\hline
\end{tabular}




\begin{tabular}{|l|l|l|}
\hline Existing Controller & \multicolumn{2}{|l|}{ Miniaturized for 1-handed walk-around } \\
\cline { 2 - 3 } Native DOFs & 1-handed walk-around usability & Manufacturability Cost \\
\hline $\begin{array}{l}\text { Thrustmaster RGT Wheel } \\
\begin{array}{l}4 \text { analog: whel, brake, clutch, } \\
\text { accelerator } \\
1 \text { digital: gear shift }\end{array}\end{array}$ & $\begin{array}{l}\text { Good for 1DOF } \\
\text { Poor for >1DOF - must use feet } \\
\text { or other hand }\end{array}$ & $\begin{array}{l}\text { Good } \\
\text { Low }\end{array}$ \\
\hline
\end{tabular}

Table 2. Assessment of potential of current 3D controllers for miniaturization for onehanded "walk around" operation.

\section{A Miniature 3D Input Device}

\subsection{Design}

This section describes the design of a prototype of a 3D controller for providing one-handed 6 DOF input with miniature size and low cost. An overview of the device is shown in Fig. 1. In terms of operation it is similar to the SpaceNavigator, providing a single grip, designed to be held between the thumb and index finger, which can be translated and rotated in 6 DOF. Movements of the finger grip are detected by an imager placed underneath, and the grip is permitted to move and rotate by a system of planar springs.

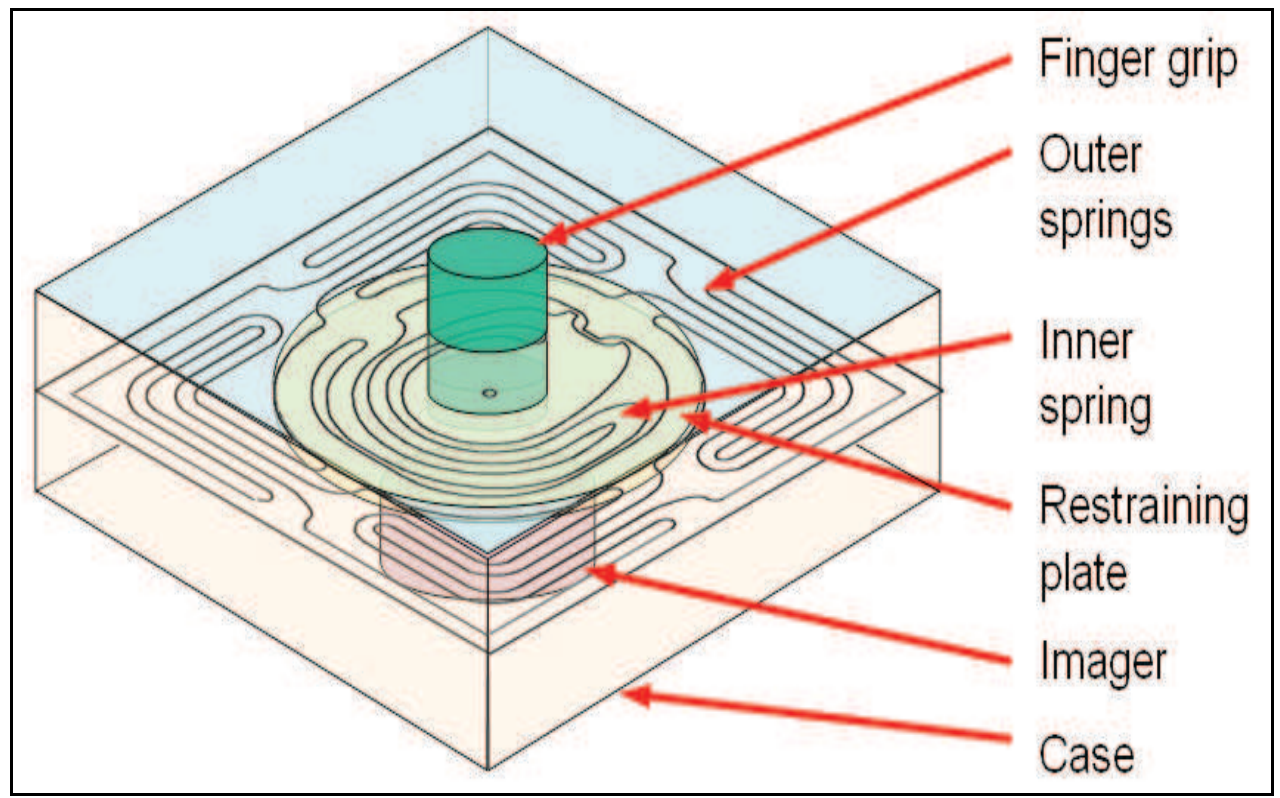

Fig. 1. Overview of miniature 3D input device prototype.

The detail of the planar spring mechanism is shown in Fig. 2. Translational and rotational movements of the finger grip move the inner frame relative to the outer frame, via the outer linear springs. With this arrangement it is relatively straightforward to design the outer springs in the L-shape shown so that the forces required to translate the finger grip and rotate it about the in-plane axes are approximately equal. However, the arrangement 
always results in the rotational stiffness of the spring about the perpendicular axis being much higher, impairing usability. To reduce the stiffness about the perpendicular rotational axis, the inner torsional spring is used. Its effect is limited to rotation about the perpendicular axis by the two restraining plates attached to the inner frame, completely enclosing the torsional spring. A circular hole in the center of the upper restraining plate allows the close-fitting grip shaft to protrude, which is fixed to the finger grip. A similar circular hole in the center of the lower restraining plate makes visible the underside of the grip mount, to which the grip shaft is attached.

To prevent excessive rotational displacement, the grip mount has two stopping tabs located on it. These tabs match a similar stopping tab on the inside of the inner frame, to limit the maximum rotational displacement approximately $8.2^{\circ}$. The outer springs self-contact to limit in-plane translation to $1.5 \mathrm{~mm}$ in each horizontal direction, and vertical displacements of the restraining plates are limited to $2 \mathrm{~mm}$ by external parts of the frame and case holding the controller. By comparison, the laptop version of the SpaceNavigator limits translational motion to approximately $1.0 \mathrm{~mm}$ in each direction and rotation to $8.8^{\circ}$.

Fig. 3 shows an assembled prototype of the planar spring made from laser-cut $2 \mathrm{~mm}$ thick Plexiglas. The black rubber finger grip is $18 \mathrm{~mm}$ in diameter and $12 \mathrm{~mm}$ high. The total functional area used by the planar spring is $50 \mathrm{~mm}$ square. The internals of a USB webcam (Logitech QuickCam, 320x240 pixels) are mounted inside the case, and the USB power is connected to two red light-emitting diodes aligned to illuminate the underside of the grip mount (Fig. 4).

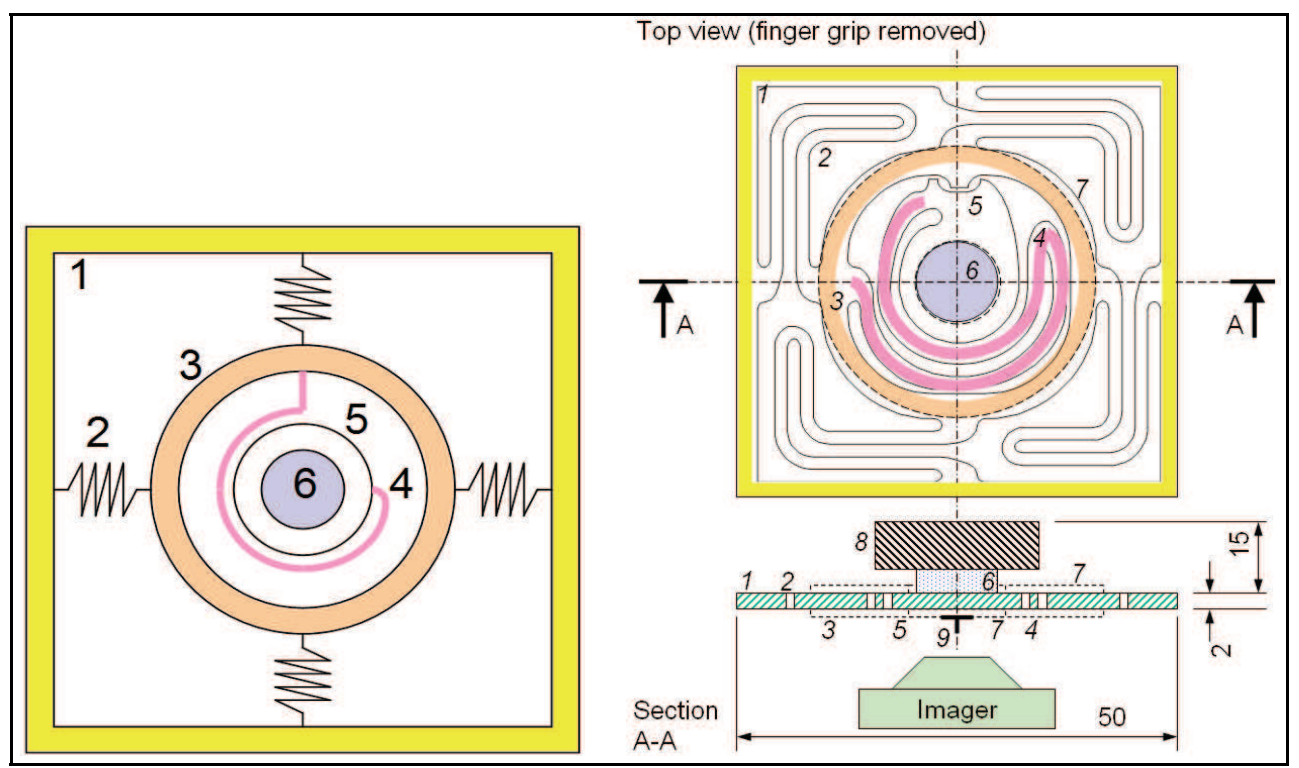

Fig. 2. (Left) Abstract model of planar translational-torsion spring mechanism. (Right) Realised design of spring mechanism. 1: outer frame (yellow); 2: outer springs; 3: inner frame (apricot); 4: inner torsion spring (pink); 5: grip mount; 6: grip shaft (light blue); 7: restraining plates; 8: finger grip; 9: index points. Adapted from (Eng 2007). 


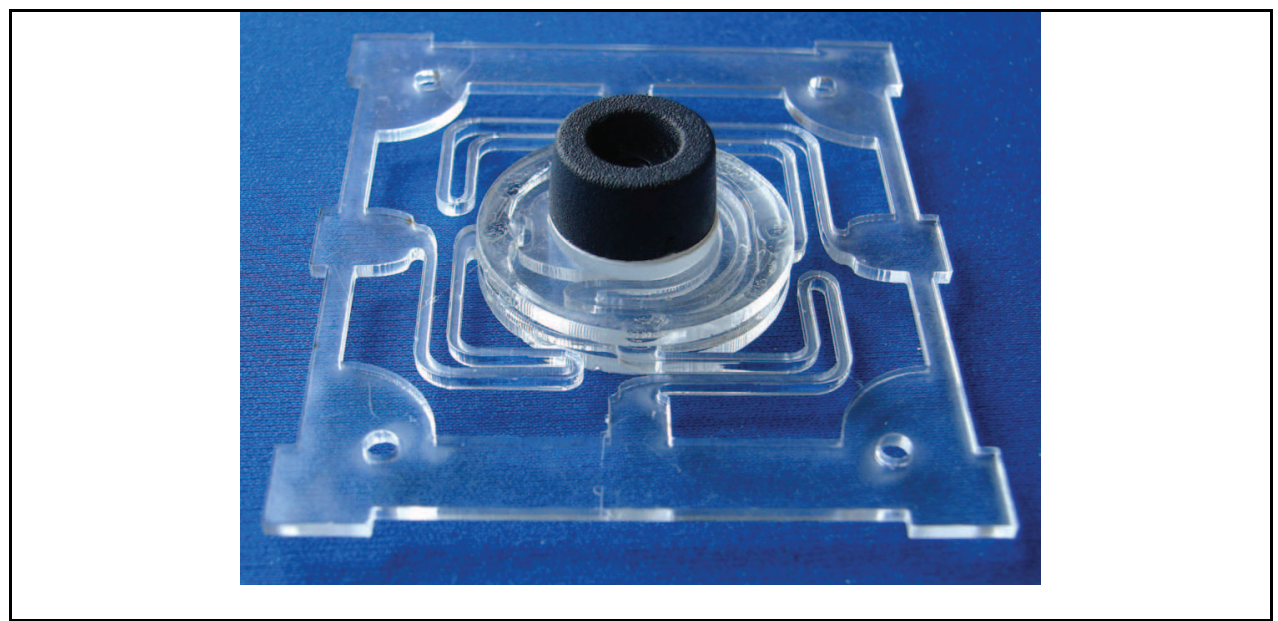

Fig. 3. (Left) Prototype spring mechanism with controller knob on top. The torsional spring can be seen inside the cavity formed by the two restraining plates.

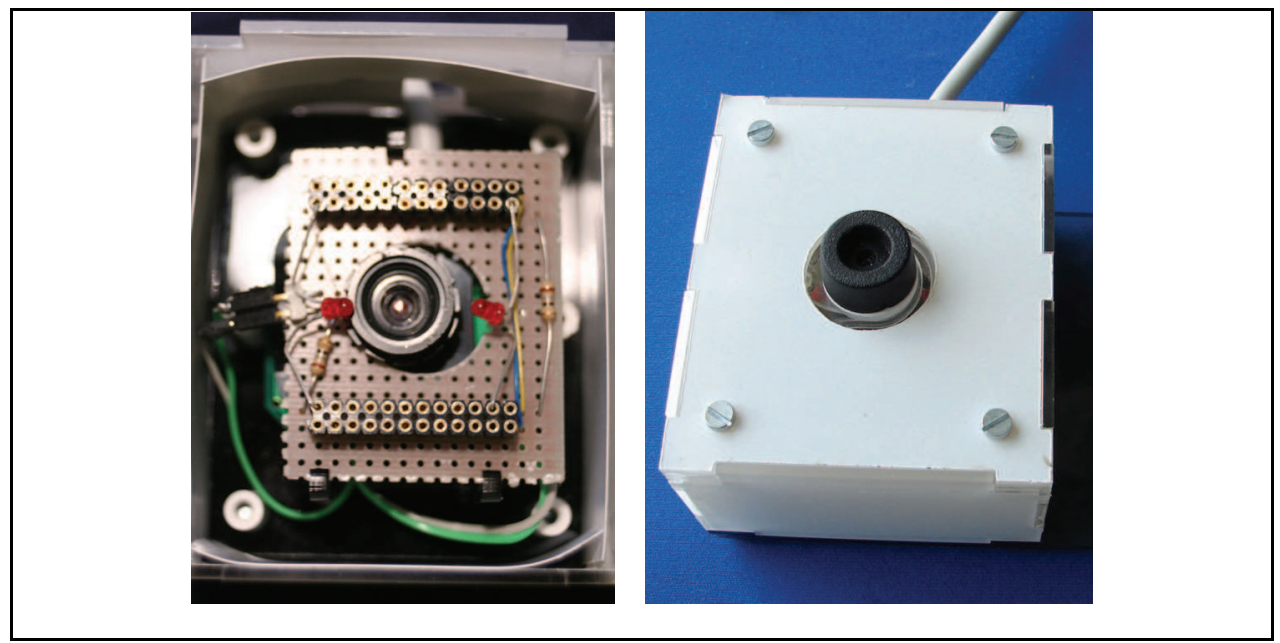

Fig. 4. (Left) Internal view of the controller, showing the webcam lens and illumination provided by two light-emitting diodes. (Right) The assembled controller.

The purpose of the webcam is to track the movements of the grip mount and therefore the user's movements applied to the finger grip. The camera tracks the movements of specially arranged white index points on a black background attached to the grip mount (Fig. 5). By considering the relative movements of the index points compared to the rest position using simple heuristics, 6 DOF simultaneous movements can be decoded using a 3D index point arrangement. If the central point is in the same plane as the other points, the number of 
DOFs that can be decoded reduces to four. In the prototype the 4 DOF version of the index point pattern was used, laser printed on normal paper. Each point was $0.5 \mathrm{~mm}$ in diameter and aligned at the corners of a square of side length $2.0 \mathrm{~mm}$. The fifth point was of the same size and set in the center of the square.

Ideally, the index points should be positioned at the exact center of rotation of the controller finger grip to avoid applied rotations about the in-plane axes causing simultaneous offset translation of the index points. These offset translations can be ambiguous and hard to decode, since they are indistinguishable from "real" translations applied to the controller. The design presented here has the index points just below the plane of the springs, which is slightly too low to be fully correct. A future improved version would feature a recess in the center of the grip shaft so that index point rotations occur about the natural center of rotation of the mechanism.

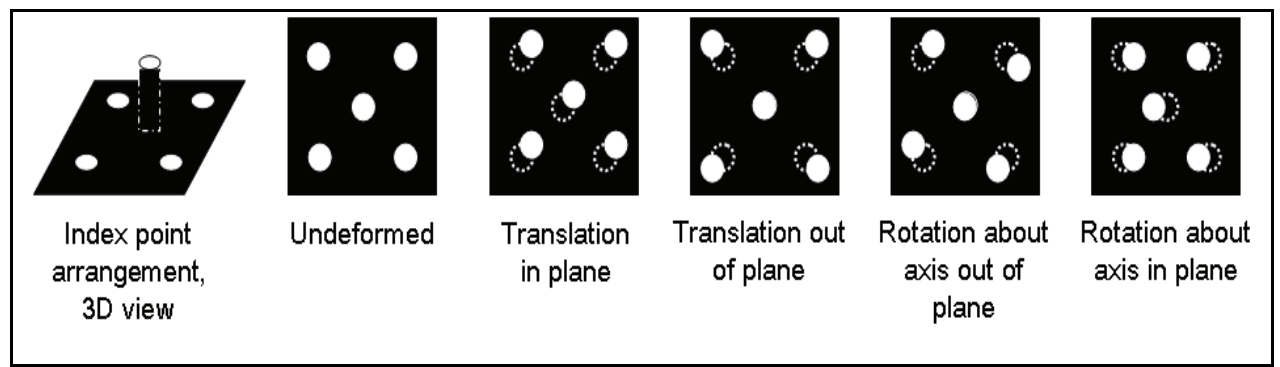

Fig. 5. Schematic of methods for deducing 3D motion from 2D motion of index points (not to scale). Dotted circles indicate original positions of index points. Adapted from (Eng 2007).

One of the biggest usability problems with all user input devices is zero-position drift. This phenomenon occurs when some hysteretic deformation or movement of the device results in the measurement of the device in the home (unloaded) position being non-zero. Applying a movement threshold often does not solve the problem on its own, as the zero position can drift above the threshold over an extended time period. It is also undesirable to use very high thresholds since it reduces the output resolution and increases the forces needed to move the device. One solution, as applied to the miniature 3D controller described here, is to have an adaptive zero level. When the current device reading is below threshold, the zero position is continually adapted slowly towards the current sub-threshold reading. The adaptation stops during above-threshold readings when force is applied to the device, and only starts again once the device has been released. Depending on the controller the adaptation process can be applied at a number of processing steps; in this case it was applied at the image processing level detecting the movements of the index points.

\subsection{Testing}

The mechanical response of the planar spring was measured as $2.2 \mathrm{~N} / \mathrm{mm}$ (horizontal plane $\mathrm{dX}, \mathrm{dY}$ ), $1.0 \mathrm{~N} / \mathrm{mm}$ (out of the plane $\mathrm{dZ}$ ) and $0.016 \mathrm{~N} /$ degree $=1.8 \mathrm{Nm} /$ degree (rotation about $\mathrm{Z}$-axis at the finger grip contact point). These figures were roughly comparable with values measured from the laptop version of the SpaceNavigator $(2.0 \mathrm{~N} / \mathrm{mm}$ for $\mathrm{dX} / \mathrm{dY}$ 
translation, $2.4 \mathrm{~N} / \mathrm{mm}$ for $\mathrm{dZ}$ translation , $0.08 \mathrm{~N} /$ degree $=3.6 \mathrm{Nm} /$ degree for rotation about the $\mathrm{Z}$ axis).

Even using the standard low-cost optics of the webcam it was possible to focus the lens reliably on the pattern of index points, corresponding to a spatial resolution of approximately $0.05 \mathrm{~mm}$. This spatial resolution corresponded to approximately $4-5$ bits of translation resolution and 3-4 bits of rotational resolution for the controller.

The controller proved to work well enough for users to position and orient a virtual cube (Fig. 6) in 4 DOF with a little practice. Because the springs were made of plastic and were thus highly damped, no measurable unwanted mechanical oscillations occurred when the user let go of the device. The tolerances involved in production of the hand-made prototype created significant zero-position hysteresis but the adaptation algorithm to eliminate zeroposition noise worked as designed. The CPU load on a desktop PC (Pentium $42.8 \mathrm{GHz}$ ) was approximately $20 \%$ including the graphics display.

No reliable method was found for producing the 3D version of the index points required to support full 6 DOF motion. Producing such small index points in 3D would require development of specialized molding or machining processes, together with methods for very precisely applying high-contrast black and white paint, neither of which were available during development of the prototype.

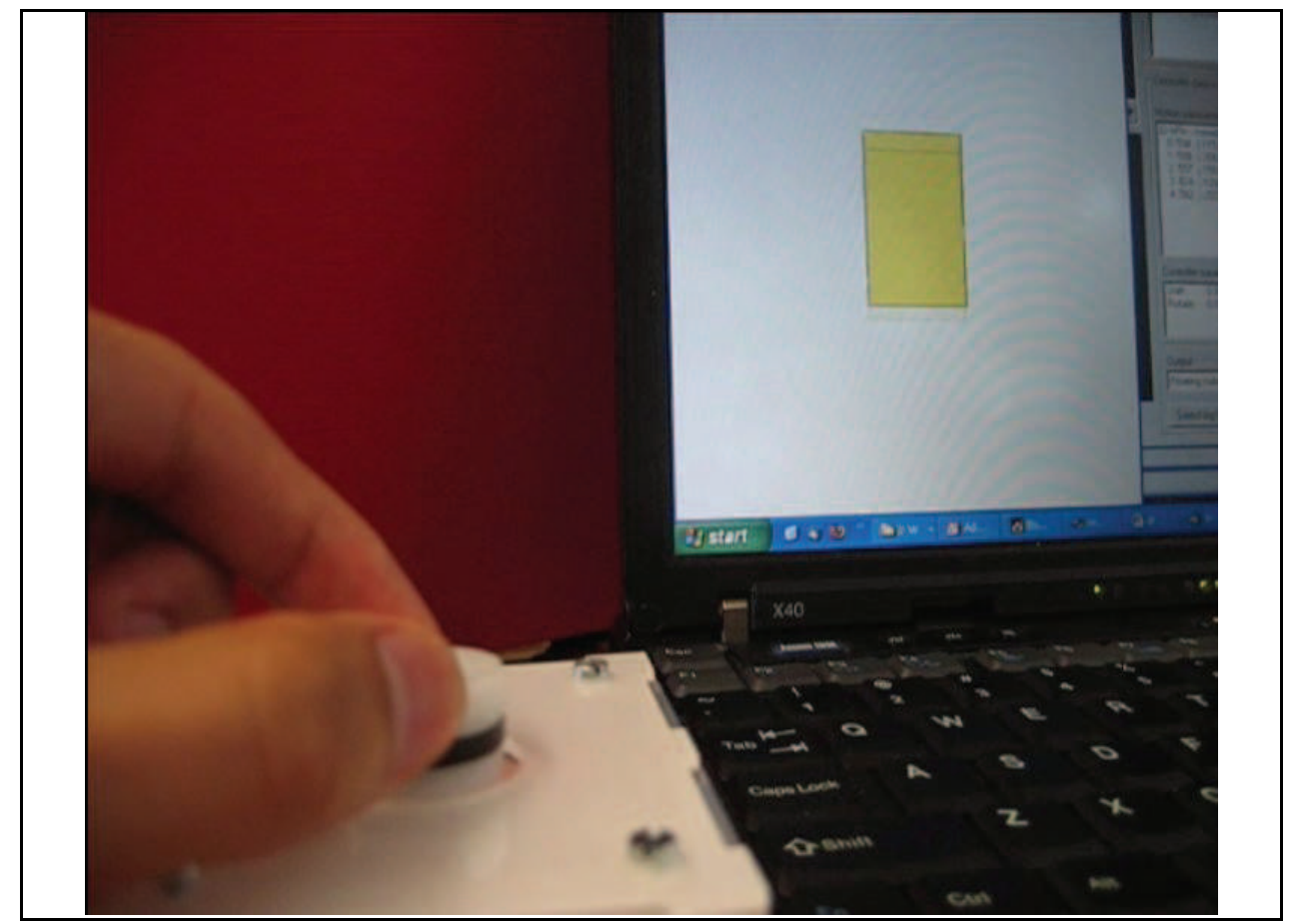

Fig. 6. Prototype miniature 3D motion controller in use manipulating a virtual cube. From (Eng 2007). 


\section{Outlook}

This chapter has outlined the requirements for creating a miniature $3 \mathrm{D}$ controller that is suitable for mobile computing applications, and presented the key elements of the design of a device fulfilling these requirements. Its key feature is a novel mechanism that provides for full 6 DOF motion using only one moving part, combined with standard image processing. While its feasibility has been demonstrated, several improvements are required to achieve a truly usable mobile controller. The two key necessary improvements include:

- Redesign the imaging device packaging and optics to reduce the depth of the controller within the case from $>40 \mathrm{~mm}$ to $<15 \mathrm{~mm}$, so that it can fit inside a typical mobile computing device.

- $\quad$ Find methods for producing the out-of-plane calibration point, probably using machining or plastic molding, so that full 6 DOF output can be supported instead of the current 4 DOF.

More straightforward improvements include further optimization of the spring design, increasing the stiffness of the casing to reduce zero-position hysteresis, and a switch to higher resolution imagers. Using a 1.3 megapixel imager would improve sensitivity by approximately 2 bits, at the cost of increasing image processing requirements. It would thus be desirable to create an embedded version of the vision processing algorithm to create a stand-alone, platform-independent device with minimal power consumption. Direct usability comparisons comparing the presented device with existing devices are also needed.

\section{Acknowledgments}

Thanks to Rodney Douglas and Wolfgang Henggeler for their advice and encouragement during the development of the device, and to Adrian Whatley for his corrections to the manuscript.

\section{References}

ARToolworks. (2007). ARTookit, from http://www.hitl.washington.edu/artoolkit/.

Bidiville, M., Arreguit, J., van Schaik, F. A., Steenis, B., Droz-Dit-Busset, F., Buczek, H. and Bussien, A. (1994). Cursor pointing device utilizing a photodetector array with target ball having randomly distributed speckles. United States Patent and Trademarks Office. United States of America.

Bisset, S. J. and Kasser, B. (1998). Touch Pad with Scroll Bar, Command Bar. WO 98/37506. WIPO, Logitech, Inc.

Eng, K. (2007). A Miniature, One-Handed 3D Motion Controller. LNCS4662 Part 1: Interact 2007, Rio de Janeiro, Brasil.

Gombert, B. (2004). Arrangement for the detection for relative movements or relative position of two objects. US6804012. USA, 3DConnexion GmbH, Seefeld (DE).

Woods, E., Mason, P. and Billinghurst, M. (2003). MagicMouse: an Inexpensive 6-Degree-ofFreedom Mouse. Proceedings of the 1st international conference on Computer 
graphics and interactive techniques in Australasia and South East Asia, Melbourne, AU, ACM Press. 


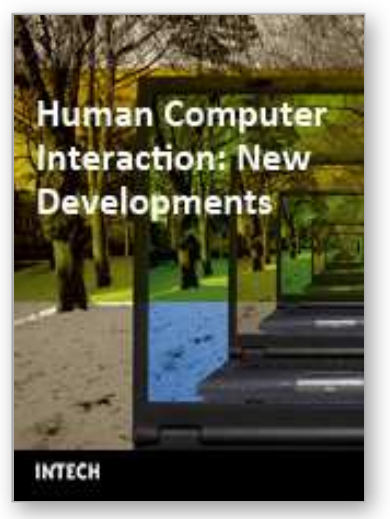

\author{
Human Computer Interaction: New Developments \\ Edited by Kikuo Asai
}

ISBN 978-953-7619-14-5

Hard cover, 382 pages

Publisher InTech

Published online 01, October, 2008

Published in print edition October, 2008

The book consists of 20 chapters, each addressing a certain aspect of human-computer interaction. Each chapter gives the reader background information on a subject and proposes an original solution. This should serve as a valuable tool for professionals in this interdisciplinary field. Hopefully, readers will contribute their own discoveries and improvements, innovative ideas and concepts, as well as novel applications and business models related to the field of human-computer interaction. It is our wish that the reader consider not only what our authors have written and the experimentation they have described, but also the examples they have set.

\title{
How to reference
}

In order to correctly reference this scholarly work, feel free to copy and paste the following:

Kynan Eng (2008). Miniaturized Human 3D Motion Input, Human Computer Interaction: New Developments, Kikuo Asai (Ed.), ISBN: 978-953-7619-14-5, InTech, Available from:

http://www.intechopen.com/books/human_computer_interaction_new_developments/miniaturized_human_3d_ motion_input

\section{INTECH}

open science | open minds

\section{InTech Europe}

University Campus STeP Ri

Slavka Krautzeka 83/A

51000 Rijeka, Croatia

Phone: +385 (51) 770447

Fax: +385 (51) 686166

www.intechopen.com

\section{InTech China}

Unit 405, Office Block, Hotel Equatorial Shanghai

No.65, Yan An Road (West), Shanghai, 200040, China

中国上海市延安西路65号上海国际贵都大饭店办公楼 405 单元

Phone: +86-21-62489820

Fax: +86-21-62489821 
(C) 2008 The Author(s). Licensee IntechOpen. This chapter is distributed under the terms of the Creative Commons Attribution-NonCommercialShareAlike-3.0 License, which permits use, distribution and reproduction for non-commercial purposes, provided the original is properly cited and derivative works building on this content are distributed under the same license. 